\title{
Branding Wakatobi: marine development and legitimation by science
}

\author{
$\underline{C h u i-L i n g}^{\text {Tam }^{1}}$
}

\begin{abstract}
Marine protected areas (MPAs) serve as a potential defense against marine degradation, meeting the conflicting priorities and needs of multiple actors. Biodiversity, conservation, and ecotourism constitute a triad of sustainability tropes in tropical MPAs that intersect with and reinterpret local histories of marine interaction, subsistence, and commercial extraction. Science is implicated in this production of resource space, with the state and other actors conscripting science to legitimate particular visions of sustainability. A content and discourse analysis of science-based communication instruments about Wakatobi National Park in Indonesia reveals a process of place branding an MPA as unique biological-economic resource space. Legitimation of science privileges scientific knowledge to promote neoliberal development as economic sustainability. Legitimation by science produces an MPA identity of a paradise of marine biodiversity worthy of conservation as ecological sustainability. And, the construction and absence of local human subjects affects their role as constrained agents in resource space. The result is weak social sustainability.
\end{abstract}

Key Words: legitimation; marine protected areas; place identity; science communication; sustainable development

\section{INTRODUCTION}

Marine protected areas (MPAs) serve as a potential defense against marine degradation, meeting the conflicting priorities and needs of multiple actors. According to the 2016 Protected Planet Report, just under $15 \%$ of the world's terrestrial and inland water systems, $4 \%$ of the global ocean, and just over $10 \%$ of coastal and marine areas under national jurisdiction are protected (UNEPWCMC and IUCN 2016). Globally, MPAs are expanding in a collective push to meet Aichi Biodiversity Target 11 for 2011-2020 adopted by signatories to the Convention on Biological Diversity (CBD), which calls for the global protected area network to cover at least $17 \%$ of terrestrial and inland water areas and $10 \%$ of coastal and marine areas by 2020 .

Marine or terrestrial, a protected area (PA) is "a clearly defined geographical space" (IUCN 2017) that can advance sustainability, commonly articulated as the three pillars or triple bottom line of environment, economy, and society (Rogers et al. 2008, Halpern et al. 2013). At their best, PAs promote "long term conservation of nature with associated ecosystem services and cultural values" (IUCN 2017), typically through an ecosystem-based or integrated multiple-use management regime wherein economic benefits are derived from nonextractive activities such as ecologically responsible tourism. The benefits of such trade-offs legitimate PAs as conservation and economic development spaces. The feasibility of trade-offs is informed by scientific data on species, populations, health, and habitats, ideally in concert with local ecological knowledge and livelihood practices (Mous et al. 2005, Saarman et al. 2013). Where trade-offs benefit most or all actors, MPAs help realize the blue economy or blue development, which Golden at al. (2017) define as an imperative whereby ocean sustainability is achieved when economic activity is in balance with the long-term carrying capacity of ocean ecosystems.

However, conservation through tourism may not always achieve win-win development. This is especially problematic in Southern countries, which command just a small proportion of global tourist arrivals and receipts (Hall 2007). In resource-dependent regions, conservation that benefits the local poor can function as pro-poor tourism (PPT), offering a viable alternative to economically driven degradation. PPT should raise the capabilities, choices, and opportunities of disadvantaged host populations, but PPT's ability to reduce poverty gaps are inconclusive and inconsistent across different southern countries (see Croes 2012). PPT variants like indigenous tourism tend to have the effect of othering indigenous peoples, provoking concerns around image, vulnerability, knowledge, ownership, and control, among others (Hinch and Butler 2005). This casts doubt on the effectiveness of globally oriented tourism spaces such as MPAs to deliver locally appropriate win-win development.

We need to ask: How do underlying extra-local sustainability discourses influence decisions made about MPA development, management, ecological and cultural tourism assets and benefits, and the relative emphasis placed on the sustainability pillars? What does this mean in areas supporting marine-dependent indigenous populations, and can these discourses be traced through published texts? Governments typically communicate their development and conservation goals for MPAs in publicly available texts such as management plans and investmentattracting information. These texts can be analyzed to determine the prominence of ecological, economic, and, of significance here, social sustainability of local populations and resource regimes that predate new MPA spatial arrangements (see, for example, Djohani 1996, Clifton and Majors 2012). Conceptual limitations and misrepresentations in policy arenas can serve "to materially cordon off, delimit, and fix the dynamics of marine-spaces and always-assembling socio-cultural interactions [and] interrelations" (Speed Rossiter et al. 2015:144); a probable outcome of these conceptual and material enclosures is the reproduction of power relations, the privileging of scientific ways of knowing, and entrenched marginalization of local actors affected by resource management.

This paper addresses blue development vis-à-vis sustainability, science communication, and place identity in the context of Wakatobi National Park (WNP) in Indonesia, informed by a hybrid content-discourse analysis of the park's investment promotion materials (produced by the Wakatobi Kabupaten government) and management plan (produced by the Indonesian 
Ministry of Forestry). The discussion addresses the legitimation effects related to science communication in WNP. It is argued that mutually supportive environmental and economic narratives, traceable through key government-produced resource management and marketing literature, produces the Wakatobi brand of a uniquely valuable biological-economic marine resource space. In this process of place branding, three mechanisms are at work. First, legitimation of science privileges scientific knowledge to promote neoliberal development as economic sustainability. Second, legitimation by science produces the park's identity as a paradise of marine biodiversity, and thus a space worthy of conservation as ecological sustainability. And third, the construction and relative absence of human subjects serves to remove local agency, conceptually and materially, from resource space. Ultimately, government communication, in the guise of science communication, coalesces as a social force that privileges extra-local priorities and narratives of marine space. The relative inattention to the local social pillar contributes to weak sustainability.

\section{Blue development, place identity, and science}

In recent years, global initiatives and institutions have equated sustainable development of marine space with blue economy or blue growth, signaling a strong economic imperative behind efforts to creatively address the fishing industry, ocean transport, marine degradation and conservation, and multiscale coordination and response (World Bank and United Nations Department of Economic and Social Affairs 2017). The global prominence of blue development is reflected in the Aichi Biodiversity Targets, the "Rio +20" United Nations Conference on Sustainable Development in 2012, the Global Oceans Action Summit for Food Security and blue growth in 2014, the five AsiaPacific Economic Cooperation (APEC) Blue Economy Forums held since 2011, and The Economist magazine's six World Ocean Summits since 2012.

Halpern et al. (2013) frame the marine sustainability challenge as inherent trade-offs to achieve the triple bottom line of conservation, economic return, and social equity, echoing the three sustainability pillars. Although blue economy is an unstable term that speaks to multiple discourses of natural capital, good business, small island developing states, and livelihoods (Silver et al. 2015), the concept implies necessary attention to ocean governance and marine resource management, and a balance among ecological integrity, economic opportunity, and human needs. MPAs are key management tools in this regard, concomitant with marine spatial planning as a system of "zoning the oceans" along ecosystem-based principles that accommodate multiple uses (Olson 2010) in demarcated and contained geographical spaces.

Given the challenges of simultaneously achieving pro-poor human development, tourism, and conservation, the efficacy of MPAs merits critical reflection, even where social sustainability is an official goal. Whereas global and national state, corporate, and civil society actors invoke economic and ecological considerations in the blue economy, its social considerations are harder to enumerate, possibly because they are so contextual and local. Sustainability fails to address distributive, political, and cultural dimensions of environmental problems (Hornborg 2009). There is a disconnect between how sustainability and the blue economy are imagined by elites, and how sustainability manifests at the local level as specific marine strategies and outcomes.

\section{MPA place identity}

As managed places, MPAs in Indonesia can be identified in large part with the consumption of tourism experience to replace income lost through reductions in local and largely extractive resource-based activities. MPAs as conservation space depend in part on tourism consumer demand, especially in Indonesia; this market rationale is mirrored in other areas of conservation and environmental stewardship. For instance, the sustainable seafood movement encourages consumers to heed the seafood source and extraction techniques (Konefal 2013). Neoliberalism prioritizes individual consumerism; individual agency allows us to make environmentally informed choices about how we consume material goods like seafood but also experiential goods such as biodiversity. Marine space is thus consumed, largely on the part of SCUBA divers and recreational seekers of sun, sand, and sea drawn to place brandings such as tropical paradise, wilderness, or unique biodiversity (Musa 2002, Cameron and Gatewood 2008, McGaurr et al. 2015). Other marine economic activities, such as alternative and/or value-added fishing industries, also sustain the blue development of MPAs (Christie et al. 2014).

According to Charles and Wilson (2009), 10 human dimensions determine the acceptance and ultimate success of MPAs: objectives and attitudes, "entry points" for introducing MPAs, effective governance, the role of rights, concerns about displacement, MPA costs and benefits, the bigger picture around MPAs, and, of particular concern in this paper, attachment to place, meaningful participation, and the "people side" of knowledge. These 10 dimensions speak to the complexities involved in using MPAs to achieve blue development. An MPA is the site of tourism-related and other economic benefits that requires the courting of marine conservationists, leisure-seekers, investors, and affected local populations. Through such endeavors at persuasion, the MPA is rebranded as leisure space, economic development space, and sustainable resource space. In that multiparty process of rebranding, the emergent MPA identity may not achieve the tripartite balance among environment, economy, and society.

State and nonstate actors' institutionalization of the sustainability discourse, and their use of cognitive models of sustainability to define outcomes as largely biological, risk obstructing substantive change toward meaningful local participation (Brosius 1999, Loring 2013). Biological cognitive models are imposed upon a cultural landscape reinterpreted as development space, which has implications for the local and/or indigenous communities already inhabiting that space. Pigg's (1992) earlier studies of Nepal are instructive. Development, she found, alters the meaning of the villager in the social imagination, fusing the local and global for economic purposes. This shapes the national imagination of the village and casts the city as the site of progress, social transformation, and modernization. Globally, conservation efforts through the establishment of terrestrial and marine PAs are part of an ecological modernization vision that reinterprets the role and legitimacy of local indigenous actors as spatially bound identities who need to be included in the project of progress. 
Ultimately, identity politics are implicated in spaces of leisure (Williams 2002). These spaces intersect with and are reshaped by narratives held by central actors such as policy makers, investors, and consumers (von Heland and Clifton 2015). In global parlance, the terms blue development, blue economy, and blue growth are used interchangeably, lending credence to the assertion that the desire to know nature in economic terms has "reverberated through environmental policy, funding and program implementation" (Suarez and Corson 2013:65). Global conservation and development discourses emerge and are maintained through the coordinated efforts of international environmental policy institutions, organizations, activists, academics, and transnational capitalist and managerial classes (Corson et al. 2013). Marine enclosures such as MPAs are one product of these intersecting discourses.

\section{Legitimation and science communication}

For MPAs, the integration of ecological, economic, and social sustainability remains problematic, especially for local fisherydependent actors, challenging the win-win discourse on conservation and development (Chaigneau and Brown 2016). As spatial entities, MPAs not only define and occupy significant ecosystems, but they are the locales where nonhuman and human populations experience, adversely or otherwise, the effects of enclosure, inclusion, and expulsion arising from new MPA arrangements such as multiple-use zones, livelihood adaptation, and financial investment (Chen and Lopez-Carr 2015). Marine biodiversity, conservation, and sustainability, propelled by the global drive to meet Aichi Biodiversity Targets and supported by science, become entangled in the pursuit of productivity and economic development, not only in service to national economic interests but also to ease the hardships caused by the MPAassociated loss of local and traditional resource-based livelihoods.

Science provides evidence of the abundance, variety, and uniqueness of wild species and helps determine threats to sustainability, thus guiding integrated or ecosystem-based approaches that reconcile social-ecological complexity and conflict; at the same time, collection of reliable statistics is particularly challenging in marine-resource rich nations such as Indonesia with its dispersed multigear and multispecies fisheries (Mous et al. 2005). Faced with the ecological and political interventions of higher authorities, local communities must adapt and seek benefits amid regime change, by turns responding as agents, as subordinates, or as a combination of both. Environmentality, the enduring relationship between government and subjectivity, suggests that changes in government will spur changes in environmental practices and beliefs among social actors, mediated through the exercise of power (Agrawal 2005). The language of policy and management, on the other hand, fails to account for power, conflicts, and inequalities (Hornborg 2009). Policy makers reveal their reasoning, decisions, and strategies within communication instruments such as management plans and investment brochures. The absence or framing of local and indigenous practices and priorities within those same documents may also reveal insights about the role that policy makers imagine for people as development subjects.

Although capital and modernity have long been scrutinized as destructive forces against ecological integrity, from a critical political ecology perspective, the construction of discourses, knowledge, and science is also implicated in environmental struggles (Forsyth 2003). Science and its deployment through various communication instruments and fora is often expected to influence policy decisions on the management of environmental goods and services (Gewin 2015, McGreavy et al. 2015) but communication also involves complex interactions linked to trust, context, networks, and stakeholder groups (Longstaff and Yang 2008, de Nooy 2013). Communicating science effectively is a chronic challenge, putting the onus on scientists to demonstrate ethical behavior and have unassailable data (Likens 2010). Science is often jargon-laden and may not be understandable to or perceived as relevant by the parties it affects; audiences, such as politicians, professional media, and agency personnel, have different expectations about how messages are conveyed and the level of technical detail they contain (Likens 2010). Nor can science easily retain its perceived neutrality amid complex politico-economic and racial histories that situate it in opposition to indigenous knowledges and the well-being of disadvantaged populations, as shown in South African fisheries (Green 2015). Science communication involves not only its content and method of delivery, but also the communicator and her/his/its motivations and allegiances. As this study shows, government can coopt science communication to legitimate its own ecological modernization vision and the imagined role of local communities.

Christie (2004) notes that biological success in Southeast Asian MPAs is usually accompanied by social failure, largely because the social dimension of MPA planning and implementation is poorly acknowledged or heeded. Likewise, the local success of policy interventions depends on a combination of scientific rigor, a concern for the human condition, and sustained engagement with stakeholders ranging from governments to farmers (Zheng and Wang 2014). As Augustine and Dearden (2014) advocate, an integrated, context-based approach cognizant and sympathetic to local realities and local ways of doing could enhance the success of MPAs. Good communication, clear, respectful, substantive, and mutually understood by experts and the lay public, is critical to such an integrated approach. Science communication affects how marine environments are produced, reconstituted, and consumed as MPAs. With reference to WNP, was its place identity changing, and was this transition reflected in the biological data used to define its value and in the promotional efforts to attract international interest to the park? Did the park management plan provide a more balanced vision of the three pillars of sustainability compared to the investment-attraction instruments? These questions concern legitimation of WNP's identity.

"Reasoning" and "giving reasons" are central to a communicative process that legitimates political institutions (Steffek 2009). Discursive legitimation, wielded by actors with differential power, is the social mechanism through which legitimation functions. It follows that science gains its persuasive power when it is communicated; marine science has power to shape marine space by legitimating resource and environmental management tools such as MPAs. Legitimacy is "a specific quality ascribed to government, or systems of governance, which generates compliance with norms, rules, and political decisions" and implies collaboration (Steffek 2009:314). Delegitimation occurs when the legitimacy of institutions, including traditional resource 
management regimes, is challenged. Legitimation struggles are common to protected areas because of the diverse and competing actors, priorities, and management strategies involved (Jamal and Eyre 2003). It can be inferred that science is implicated in legitimation struggles over the purpose and identity of MPAs.

\section{METHODS}

\section{Location}

In the last two decades, the 1.39 million-hectare Wakatobi National Park (see Fig. 1) has been reborn as both national MPA and as Wakatobi Regency within the Indonesian province of Southeast Sulawesi. It is an historically economically disadvantaged region and the new government is actively pursuing economic development. Established in 1996 after a program of data collection by marine biologists on the health of fish species and coral reefs, WNP has been dogged by local community grievances, largely around restricted access to traditional fishing grounds, confusion over the legality of certain spaces and harvesting practices, and lack of alternative livelihood options (Berdej et al. 2015, WWF 2018). Community disaffection with the original WNP management regime, especially as it related to livelihood restrictions, was a key impetus behind the rezoning of WNP in 2007, involving public consultations among its roughly 100 villages and 100,000 inhabitants.

Fig. 1. Wakatobi National Park.

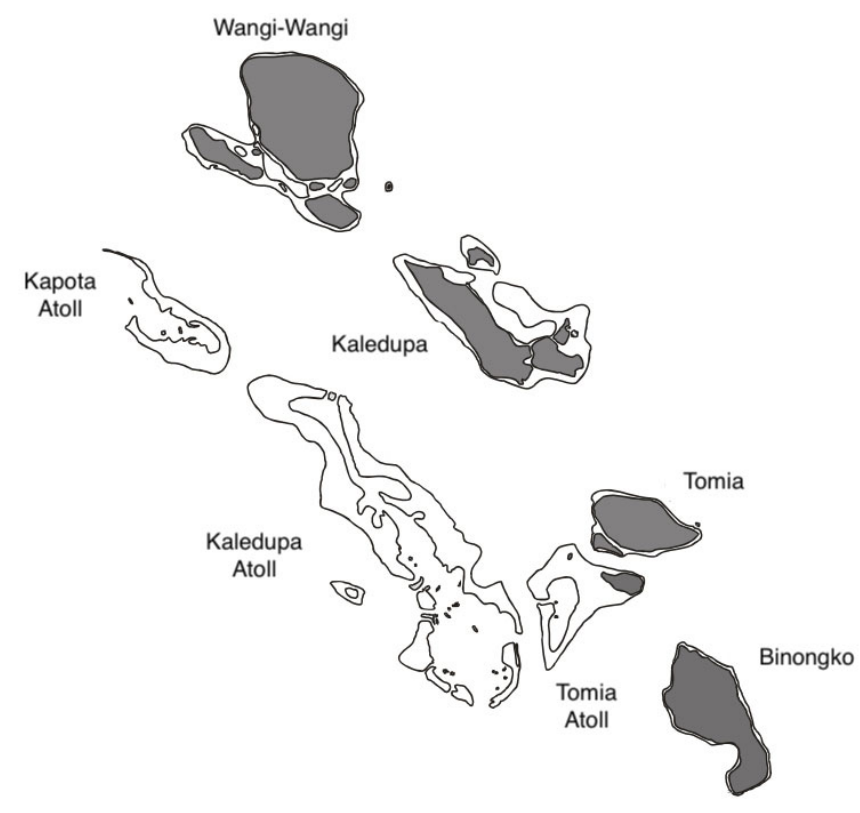

WNP is one of Indonesia's most celebrated MPAs, securing the status of United Nations Global Biosphere Reserve in 2012. Marine sustainability is of critical importance to Indonesia, the world's largest archipelago. Its coastal and marine economic activity accounts for one-quarter of gross domestic product and employs more than $20 \%$ of the country's workforce; some $65 \%$ of the population lives within 50 kilometers of the coastline (Dahuri 2006). WNP is part of the six-nation Coral Triangle Initiative, a 647-million-hectare ecosystem at the confluence of the Indian and Pacific Oceans that supports $76 \%$ of the world's known coral species, $37 \%$ of the world's fish species, and 120 million people (CTI 2019a). Indonesia's push for intraregional cooperation in CTI was driven by "the critical need to safeguard the region's marine and coastal resources," of which $95 \%$ of the coral reef ecosystem is at risk (CTI 2019b). There are four main islands in WNP: Wangi-Wangi, Kaledupa, Tomia, and Binongko, with associated ethnic groups.

In Wakatobi government literature, WNP is branded as the physical and spiritual "Heart of the Coral Triangle," a reference to both Indonesia's leadership within CTI and WNP's location in CTI's proximate physical center. Marine biodiversity has become Wakatobi's brand identity, maintained by discursive mechanisms that extoll its environmental-as-economic value, supported by science as evidence. Dive tourism is a growing business, and value-added alternative marine industries are encouraged, underpinning continued expansion of seaweed aquaculture, seafood snacks, and artificial fishing lures. Although politicians, managers, and NGOs speak an extra-local narrative of sustainable development, the author's direct communication with villagers unearthed proportionately more negative than positive accounts of the park's impacts on local communities (see Tam 2015). The villagers supported the idea of sustainability, but disputed whether sustainability was achieved in practice at the community level. It appeared that, amid WNP's developmental transition, it was largely represented as ecological space and economic space, but its significance as social and cultural space was diminished. This study, focusing on three communication instruments prepared by Wakatobi authorities, is an attempt to reconcile the dominant local vs extra-local narratives that the author encountered.

\section{Data collection and analysis}

Since the 2007 rezoning, Wakatobi revised the park management plan officially based on community consultation, aided by a collaboration in place since 2002 between WWF and The Nature Conservancy (TNC) to assist the WNP authority to "implement effective management strategies informed by the best science and local socio-economic realities" (WWF 2018). Initiatives include a zoning system, awareness raising, management training, economic and community development, fisheries, management and policy reform, and species monitoring. As part of its development pitch, the Wakatobi government produced an investment book for distribution to potential investors and a PowerPoint slide roadshow to sell WNP's multiple attributes. The author conducted a discourse-content analysis of the communication instruments-management plan, investment book, and slide show - to determine the manifestations of marine science, economy, and people.

The author, an Indonesian speaker, conducted secondary datagathering and fieldwork for a new study in Wakatobi National Park in 2017, as well as casual conversations and 30 semistructured interviews in WNP with villagers, NGOs, and government staff during three site visits between 2007 and 2013 . She sought to determine whether villagers' negative experiences (Tam 2015, von Heland and Clifton 2015) could be corroborated through analysis of the Wakatobi government's own published literature. For a working typology, she interrogated the communication of science with four phenomena in mind: (i) the methods/instruments of communication, (ii) the substance of the 
Table 1. Content in three communication instruments in Wakatobi National Park (WNP).

\begin{tabular}{lccc}
\hline \hline Key Images and Narratives of Wakatobi & & Proportion and/or frequency of topical content \\
\hline & 2009 Slide show & 2010 Investment book & 2008 Management plan \\
\hline Total Units & 36 slides & 45 pages & 110 pages \\
& & & \\
Biodiversity/natural beauty & High & Medium & Low \\
People as cultural assets & High & Medium & Low \\
Tourists as consumers & High & None & None \\
Demographic data & Medium & High & Medium \\
Scientific data & High & High & Very high \\
Tourism economy & Medium & High & High \\
Fishery \& marine economy & Medium & High & Very high \\
Local livelihoods & Low & Low & Low \\
\hline
\end{tabular}

communicated science, (iii) the active and passive voices in communication, and (iv) the location of science as communicated knowledge.

Content analysis of text and images identified frequent and dominant words, phrases, and themes. The documents analyzed were the 36 slides in the Wakatobi government's English-language presentation to investment and government bodies, the 45-page Indonesian-language investment book produced by the regional development agency, and the 110-page WNP resource management plan. For the management plan, passages highlighted in the content analysis were then run through the free online tool Google Translate, followed by manual review of the generated translations. Using thematic coding, the author searched for representations of different place and people identities including masyarakat (community), manusia (human), nelayan (fisherman), pegawai (employee/worker), ilmu (science), tradisi (tradition), pengetahuan (knowledge), budaya (culture), wisata (tourism), and mata pencaharian (livelihood). The author also drew insights from her interviews (namely, poor communication with villagers and local economic hardships related to the park use zones), and was mindful of the missing actors and spatial imaginaries, i.e., social constructs of space and its contained objects, in the three communication instruments in question. Using discourse analysis, she looked for constructions and absences of those same identities.

This hybrid discourse-content analysis supports the idea that the analysis of informal documents can complement other research methods and data (Hutchins and Stormer 2013) such as participant-observation, interviews, and public hearing transcripts (or resource management plans) in order to excavate place identity and the processes through which it is formed. This multiperspectival approach mixes quantitative and qualitative data (Feltham-King and Macleod 2016) but is also methodologically informed by an ethnographic sensibility (Altheide 1987, Anderson 2012, Townsend 2013, Scholl et al. 2014). The point is to sift through numeric and narrative data to interrogate the privileging of science, its use in economic strategy, and the way it is implicated in social constructions of marine space and peoples. This is critical given the conservation rationale that an MPA's touristic value can largely replace its extractive value, supplemented by investment in alternative marine livelihoods. This MPA place branding, to adapt King (2005:355), "perpetuates the distinction between those who produce and those who consume, and as some people catch fish for many others, most people experience the ocean in absentia. Unchallenged by conflicting experiences, the public is potentially able to imagine an ocean ecosystem without humans." The results suggest, if not the complete absence of local humans in the WNP communication instruments, then certainly a lack of recognition or thinness of engagement with socially complex communities with their own histories of marine spatial interaction.

\section{RESULTS}

Results suggest that communication of science is effective in disseminating information about WNP's biological diversity and its blue growth potential, referenced in the trope "Heart of the Coral Triangle" invoked in government literature and by government staff in conversation. Attention to social sustainability is low in investment-oriented communication instruments, which was not a surprise. Of greater concern is the relative space allocated to drawing out the complexities of local livelihoods in the WNP management plan, and the widespread portrayal of local peoples as cultural tourism assets. The topical content of the three communication instruments are summarized in Table 1, with indicative terms for the relative weighting of key images and narratives of WNP.

\section{Investment slide show}

The investment slide show was designed in 2009 as a persuasive presentation for delivery to other government officials and potential investors by Wakatobi's bupati, the elected head of the regency. Its 36 slides were dominated by three narratives of WNP. These were the natural beauty of WNP, its interesting cultural groups often pictured performing a traditional ethnic dance, and tourism (represented by a female Caucasian model positioned in scenes of white sand beaches, clear blue waters, and/or palm trees). Of 58 images, 23 were nature photos and six were maps. The remaining half of the photos consisted of nine images of the Caucasian model, five images of historic sites or crafts, 14 images of local people as cultural tourism assets (see Fig. 2), and one image of a fishmonger's wares with shoppers in the background. Measured in terms of proportion of the slides, a high amount of content was the equivalent of six to seven slides, medium amount was two to three slides, and low amount was negligible at a fraction of one slide. Text-free slides were counted as separate units from slides with textual content. Textual details focus on (i) the two leading sectors of "fisheries and marine" and "tourism," (ii) 
biophysical data on coral reefs, islands, and species and fishery production estimates, and (iii) tourism information such as accommodation, cultural spectacles, and diving activities.

Fig. 2. A slide showing cultural tourism assets.

\section{KARIA - A TRADITIONAL PROCESSION}

- Executed Massly by Local People

- Celebration of Children Circumcision (Sunatan)

- Stretched around

the village

- Usually conducted

after Praying "Idul Adha"

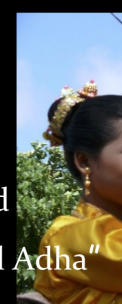

\section{W.}
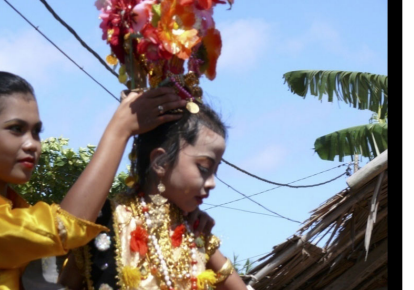

\section{Investment book}

The 45-page black-and-white Profile of Investment Opportunities, commonly referred to as the investment book by civil servants, was published in 2010 by the Wakatobi development agency, BAPPEDA. Its full-color cover folds out to a map of WNP overlaid on its edges with nature and people photos and textual highlights of the economic potential of fishery and marine, agriculture, forestry, and tourism (culture, beach, and sea). Within the first seven pages are a general description of Wakatobi regency including its geography, people (roughly one page long with one paragraph on population and three paragraphs on local educational attainment, both accompanied by a table), and other concise details about facilities, infrastructure, and the legal structure of Wakatobi. The biggest section comprises 27 pages on investment potential and opportunities, primarily asserting its biophysical resources for extraction, supported by 25 small photos of individual fish species, 17 photos of underwater and beach scenes, plus four photos of coral farming, with 16 pages on tourism of which five pages feature sea and beach potential and 11 pages feature cultural potential accompanied by 22 photos of historical sites, craft making, ethnic dances, and local boats and buildings. In terms of pages committed to each phenomenon, a high amount of content filled at least 11 pages or $24 \%$ of the book, a medium amount of content was between 2 and 10 pages, and very low was less than one page.

\section{WNP management plan}

The 110-page Wakatobi National Park Management Plan 1998-2003 (2008 Revision) states in its Chapter I Preface (pages 1-4) that WNP was established as a buffer system to secure biological conservation and guarantee sustainable development and sustainable community livelihoods. The Chapter II Area Description (pages 5-31) commits three pages to regional history, 15 pages to the biophysical system, two pages to physical travel logistics, one page to human demographics, two pages to the

"socio-economic and cultural conditions of the community," two pages to institutional structure, and four pages to human resources, e.g., marine patrols, and supporting facilities. Chapter III Policy (pages 32-36) lists social sustainability challenges such as participation, economic and community empowerment, poverty and unemployment. Chapter IV Vision and Mission of Wakatobi National Park Management (pages 37-45) asserts a vision of the "realization of a steady, dynamic and sustainable [WNP] that can provide benefits to the community and region in a sustainable manner," largely through a zoning system to regulate multiple economic activities, sound waste management, and development of marine tourism. Chapter V Analysis and Protection (pages 46-87) focuses on ecological pressures including destructive local fishing practices such as the use of explosives and chemicals. Chapter VI Plan of Action (pages 8897) includes two pages on a program to raise community awareness, increase participation, foster community empowerment in and around WNP, and develop an information and communication system for the wider community (national and international) as a medium of education, counseling, and promotion. The Chapter VII (pages 98-110) Conclusion summarizes the management plan in a large matrix of five tables.

Attention to pengembangan partisipasi masyarakat (development of community participation) is captured in one short paragraph less than one-third of page 96 stating: "The development of community participation is intended to encourage an increasingly active role of the community in the field, so that the management of WNP becomes more effective and efficient and fully supported from the community and all parties. This is realized through clean beach activities, mangrove tree planting and preventive public security." In sum, only about two pages of text address community engagement (less than $2 \%$ of the page count) and seven pages to general social considerations or demographic data $(6.5 \%$ of total pages), compared to 75 pages $(68 \%)$ to aspects of the biophysical system and tourism, fishery and marine economic management.

\section{Low visibility of social sustainability}

Low visibility is signified by absence from the government literature. There is low visibility of local populations as active agents with their own histories of occupation, resource tenure, and adaptation. The slide show and investment book demonstrate a strong bias toward WNP as a biologically unique space that can be exploited for its tourism potential and fishery and marine potential. The management plan devotes the greatest attention to marine ecological resources and, to lesser extent, social sustainability challenges such as destructive fishing practices, local dependence on fisheries, and the need for alternative livelihoods.

Wakatobi's assets are captured in its brand identity "Heart of the Coral Triangle." WNP is highlighted as a rectangle in the map of the Coral Triangle on the cover of the investment book (Fig. 3) and in the title of the slide show (Fig. 4). In the park management plan, the heart is shown as a large red dot on a map on page 11 of the 110-page document. The heart is a reference to Indonesia's political place in CTI, WNP's physical place in the Coral Triangle, and its social-ecological place at its center. In all three instruments, local people are portrayed largely as cultural commodities or development subordinates that can be mobilized for tourism. 
Fig. 3. Cover of investment book.

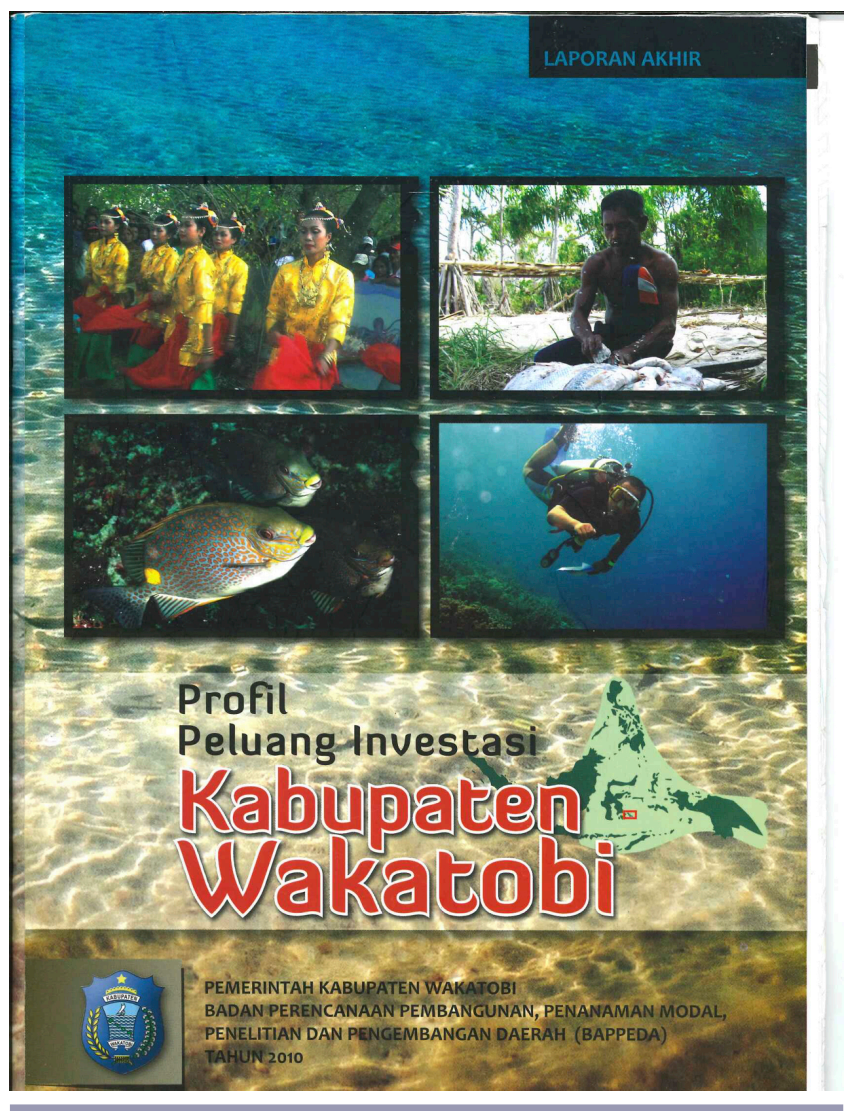

Fig. 4. Title of slide show.

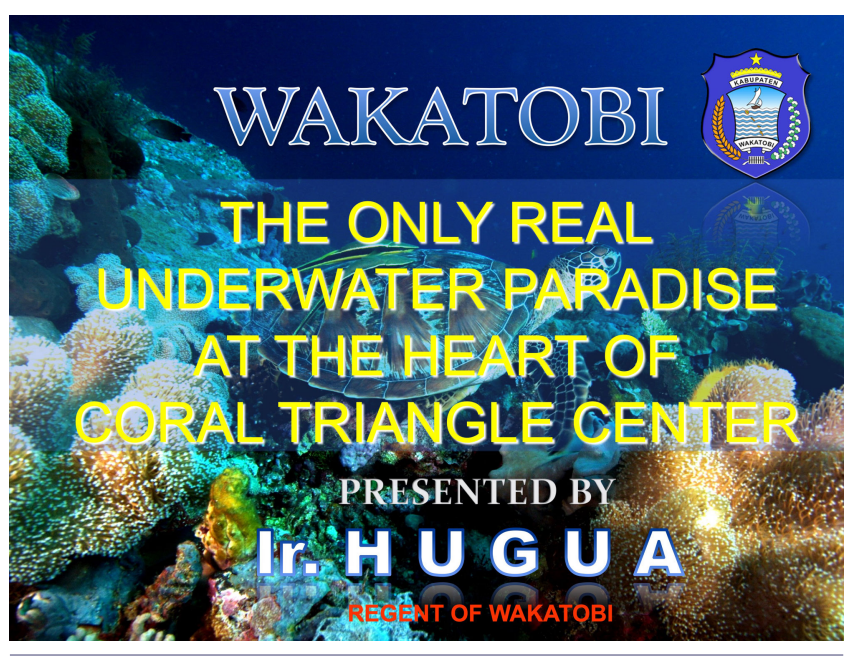

\section{DISCUSSION: SCIENCE OF BLUE BRANDING}

The present study exposes two tensions at the intersection of communication and place. The first tension is the deployment, i.e., the communication, of science to legitimate the establishment of an MPA and its management regime. This process, reinforced by partnerships between state and environmental NGOs, exemplifies the environmental institutionalization that Brosius (1999) warns about. The second tension is the triad of science-connected tropes with which MPAs are identified, biodiversity, conservation, and ecotourism, and how these tropes serve to reinforce an outward-oriented $3 \mathrm{~S}$ "sun, sand, and sea" aesthetic that intersects with and reinterprets local histories of marine interaction, subsistence, and commercial extraction. These tensions in science communication relate to how WNP is constructed through information, investment, and resource management materials, thereby creating a place identity or "Wakatobi brand" for public consumption. For tropical MPAs, biodiversity, conservation, and ecotourism constitute a powerful triad of sustainability tropes justifying the enclosed space of the MPA; blue development driven by tourism market demand is intrinsic to MPA place identity.

As Hutchins and Stormer (2013:35) argue in their study of online responses to newspaper articles concerning a land-use controversy, "identity is a changing and traceable element of place that is responsive to and interacts with system disruptions, like land-use events [such that] texts performatively (re)arrange identity as part of the rezoning proposal event itself." This study of WNP communication instruments demonstrates that the communication of a resource management regime and the justification of that regime is supported by science such that a new marine resource identity emerges even as other identities of place and place-specific peoples are suppressed. This study demonstrates the usefulness of a methodology that examines how texts serve as discursive practices that shape marine users', investors', and managers' relationships with marine resource access, recreation, and economy amid the social system disruption represented by the establishment of an MPA and a new government in Wakatobi.

\section{Visual and textual narratives}

The MPA as a new form of enclosure in the blue economy must be justified on the basis of available scientific data. Marine science underpins all three communication instruments studied here. As a result, the first narrative of marine biodiversity and natural beauty is powerfully anchored by data on species diversity and WNP's central place at the Heart of the Coral Triangle. To justify the inevitable curtailment of older local regimes of resource use, the economic promise of Wakatobi emerges as a second narrative, a promise made on the basis of scientific estimates of marine species productivity. Finally, as marine space is enclosed, so too are its human inhabitants, whose ethnicities align with the four main islands; various seafaring and coastal communities also identify with their origin villages and their particular island of residence within WNP. The result is a mixture of cultural groups with different languages, customs, dress, and cuisines that are reimagined, in the new MPA economy, as "cultural assets." In this way, touristic space and culture become the third narrative evident in WNP.

\section{Legitimation of science}

Evidence from the three communication instruments suggests that local knowledge is poorly integrated or unsought, such that science is legitimated as the knowledge that matters. Effectively, local knowledge is discursively delegitimated by its absence or thinness in key WNP management policy and marketing documents. 
The prolific use of marine biotic data in all three communication instruments reinforces the perceived value of science against the absence of traditional knowledge. In the slide show and investment book, there is no pretense to address local people as ecological or economic agents, and likewise local and traditional knowledge simply are not invoked. In the management plan, local people are acknowledged as economic actors but there is no hint of the knowledge they can offer; their engagement in knowledge is imagined in the role of information receivers who will become more "aware," "participative," and "empowered" through a management program to integrate them into an MPA not of their design. Marine science is juxtaposed against and often methodologically ill-equipped to collect data about social phenomena (Christie 2004) such as local/traditional ecological knowledge, customary marine tenure, social networks, and relations across marine space, and uneven access to political participation.

This study sheds light on discursive legitimation, defined as the social mechanism through which legitimation functions; its key participants, in order, are (i) state representatives such as politicians, civil servants, and diplomats, (ii) experts, (iii) activists and lobbyists, (iv) journalists, and (v) citizens (Steffek 2009). The authorial voices, especially in highly technical matters, belong to bureaucrats, technocrats, and experts. Whether in poor communities such as WNP or among affluent, educated, engaged, and democratic public spheres such as the Canadian Rockies mountain park destination of Banff, "human participants may be subjected, shaped and sometimes enabled, sometimes constrained, by legitimation struggles between environmental, business, park and other public interests" (Jamal and Eyre 2003). The net result is the potential absence and incoherency of a broader public discourse on a given environmental issue, with the average citizen in the local community coming last.

\section{Legitimation by science}

As marine policy tools, MPAs are discursively embodied in representations of space, i.e., policies and practices expressed as park management plans, investment brochures, and investment attraction materials. Such representations reimagine and rebrand historically lived marine spaces as conceived spaces of sustainable development made possible through conservation. WNP is valued by powerful institutions as a marine space of unparalleled biodiversity and uniqueness, where conservation is under threat and management is the remedy (von Heland and Clifton 2015). Articulations of place identity are traceable through communication in particular locations and scenes that are, in effect, constantly reassembling as humans interact with marine space (Hutchins and Stormer 2013, Speed Rossiter et al. 2015). Thus, how science is deployed communicatively has implications for which place identities emerge, whether unique biodiversity, economic growth opportunity, or global/local marine commons.

In MPAs, when science is established as valuable, it legitimates the economic potential of natural resources. The economic prerogatives within sustainable marine development are neatly reflected in the interchangeability of the terms blue development, blue economy, and blue growth. MPAs thus become managed development space under new regimes of zoning and enclosure, which may inspire unhappiness among locals confused by the boundaries and legality of their activities at different sites and times. It is vital to ask how the communication of science, sustainability, and economy affects the production of marine space. In WNP, economic sustainability is legitimated by science and its communication in terms of content about environment, economy, and society, and the relative absence of content about the diversity and complexity of local people who already command knowledge of their marine world.

Science is implicated in representations of space, and flawed science communication can affect imaginaries of marine space and space-defining policy and practice in ways that harm the sustainability of pre-existing social systems in an MPA. The question here is how the communication of science discursively affects marine space and the legitimation of marine actors who have potentially conflicting priorities for that space. This has implications for the role of science in the social production of resource space and how the state and other actors conscript science to legitimate particular translations of sustainability. Biodiversity, conservation, and ecotourism constitute a powerful triad of tropes in this discursive process of legitimation by science. Theses tropes are vital to the place branding of MPAs like Wakatobi.

\section{Construction and delegitimation of community}

The legitimation of science and the legitimation of enclosure and neoliberal economic growth by science, while perfectly rational in the branding of MPAs like Wakatobi as win-win development spaces that promote ecological and economic sustainability, are troubling amid the absence of complex and nuanced local identities and the externally produced construction of touristically valuable local identities. An integrated approach is incomplete without context-based knowledge (Augustine and Dearden 2014). Legitimation of and by science risks reproducing the frequent failure of scientists and managers to engage effectively with local populations or to understand the worldviews that shape their interactions with marine space (Clifton and Majors 2012, Tam 2015).

There are two imaginaries or false visions of Wakatobi. One relates to King's (2005) observation that the oceans as a global concern reflects an ontology of a "contemplated" ocean that is human-free and should be appreciated from afar, and in which certain fishers may be perceived as transgressing on the "natural" boundary between humans and the environment. As such, in Wakatobi, the immediacy of fishers' livelihoods and other interactions with the ocean are regulated and legitimated by the design of the MPA, biological science, and extra-local economic priorities. In other words, this is a Wakatobi imagined from afar, by forces who do not experience it as their everyday reality. This imaginary delegitimates the direct interactions that maritime peoples have with the ocean.

The second imaginary emerges most clearly in the two investment communication instruments, and to an extent in the management plan: local communities are discursively identified as cultural commodities. Marine peoples are idealized as a contemplated product in a contemplated ocean. Or, in economic parlance, locals are another factor of production alongside biophysical marine resources; together they form the Wakatobi advantage and are part of a package to attract investors and tourists. This reflects the economic rationality behind blue development. As contemplated products, where is local people's voice? What would it say? 
The WNP management plan proffers a more nuanced imaginary of Wakatobi's residents compared to the blatant economic narrative of the slide show and investment book. But the management plan also predates the other two instruments, whose existence and tone arguably take their direction from the way marine sustainability is presented in earlier government documents. Therefore, the relative inattention to local realities and complexities in the management plan destabilizes the social sustainability pillar in WNP. Although the management plan recognizes the poverty and marine dependence of local populations and the need to help them, the treatment of these issues is cursory. It is not robust in social scientific terms. Marine biotic data shape the identity of WNP, but in concert with government economic priorities and promotional efforts to attract investment and visitors, and the introduction of new forms of economic activity in a previously remote and economically disadvantaged area.

In the branding of Wakatobi, legitimation of and by science intersects with the construction of people as tourism products and their absence as active actors in marine space. The audience exposed to the WNP management plan, the travelling slide show, and the investment book is no wiser to the stories of local people as livelihood practitioners, environmental stewards and managers, agents of transformation, or decision makers. Marine place is deidentified as lived social space and legitimated as ecological and economic space.

\section{CONCLUSION}

Scientific knowledge is a communicative force that shapes the management of resilient ecosystems, by turns juxtaposed unfavorably against or integrated conscientiously with local ecological knowledge. Science is implicated in the way resource space is managed and produced. It is implicated in the branding of conservation space. We need to interrogate whether and how scientific knowledge is conscripted into various imaginaries of place and the priorities of the governing bodies that, as development actors, legitimate conservation spaces. Biodiversity, conservation and ecotourism constitute a powerful triad of tropes in a science-based narrative in this process of legitimation.

An analysis of information and investment materials related to Wakatobi National Park reveals that mutually supportive environmental, political, and economic actors control the production of the protected area as an economic and ecological success story. In a "sustainable development" transition, conservation space is identified foremost as physical and economic space, while local populations who experience these areas as lived space are commodified and rebranded as one among many products to be managed, harvested, and consumed, raising questions about social sustainability. WNP demonstrates that a successful branding of conservation as development depends on three things: first, strong science to demonstrate need for and value of conservation; second, established, emergent, or cultivated market demand for conservation; and three, an export orientation for conservation-friendly development. Export orientation has as its mandate the purpose to exploit comparative advantage and increase earnings through foreign consumption of local goods. In WNP, those goods are aesthetic (natural beauty), biophysical (marine fishery and resources), and cultural (people). The communication of science contributes to imaginaries of place in the blue economy through the methods and instruments of communication, the substance of the communicated science, the active and passive voices in communication, and the position of science as communicated knowledge.

Responses to this article can be read online at: http://www.ecologyandsociety.org/issues/responses. php/11095

\section{Acknowledgments:}

The author would like to thank the anonymous reviewers for their careful observations and insightful suggestions, She gratefully acknowledges the support of the University of Calgary, University Research Grants Committee, which provided funding for this study.

\section{LITERATURE CITED}

Agrawal, A. 2005. Environmentality. Current Anthropology 46 (2):161-190. https://doi.org/10.1086/427122

Altheide, D. L. 1987. Ethnographic content analysis. Qualitative Sociology 10(1):65-77.

Anderson, C. M. 2012. Lost in space? Ethnography and the disparate geographies of social process. Professional Geographer 64(2):276-285. https://doi.org/10.1080/00330124.2011.600221

Augustine, S., and P. Dearden. 2014. Changing paradigms in marine and coastal conservation: a case study of clam gardens in the southern Gulf Islands, Canada. Canadian Geographer 58 (3):305-314. https://doi.org/10.1111/cag.12084

Berdej, S., M. Andrachuk, and D. Armitage. 2015. Conservation narratives and their implications in the coral triangle initiative. Conservation and Society 13(2):212-220. https://doi. org/10.4103/0972-4923.164208

Brosius, J. P. 1999. Green dots, pink hearts: displacing politics from the Malaysian rain forest. American Anthropologist 101 (1):36-57. https://doi.org/10.1525/aa.1999.101.1.36

Cameron, C. M., and J. B. Gatewood. 2008. Beyond sun, sand and sea: the emergent tourism programme in the Turks and Caicos Islands. Journal of Heritage Tourism 3(1):55-73. https://doi. org/10.1080/1743873X.2008.9701250

Chaigneau, T., and K. Brown. 2016. Challenging the win-win discourse on conservation and development: analyzing support for marine protected areas. Ecology and Society 21(1):36. https:// doi.org/10.5751/ES-08204-210136

Charles, A., and L. Wilson. 2009. Human dimensions of marine protected areas. ICES Journal of Marine Science 66(1):6-15. https://doi.org/10.1093/icesjms/fsn182

Chen, C., and D. Lopez-Carr. 2015. The importance of place: unraveling the vulnerability of fisherman livelihoods to the impact of marine protected areas. Applied Geography 59:88-97. https://doi.org/10.1016/j.apgeog.2014.10.015

Christie, N., K. Smyth, R. Barnes, and M. Elliott. 2014. Colocation of activities and designations: a means of solving or 
creating problems in marine spatial planning? Marine Policy 43:254-261. https://doi.org/10.1016/j.marpol.2013.06.002

Christie, P. 2004. Marine protected areas as biological successes and social failures in Southeast Asia. American Fisheries Society 42:155-164.

Clifton, J., and C. Majors. 2012. Culture, conservation, and conflict: perspectives on marine protection among the Bajau of Southeast Asia. Society \& Natural Resources 25(7):716-725. https://doi.org/10.1080/08941920.2011.618487

Coral Triangle Initiative (CTI). 2019a. Frequently asked questions. Coral Triangle Initiative on Coral Reefs, Fisheries and Food Security. [online] URL: http://www.coraltriangleinitiative.org/ $\underline{\text { frequently-asked-questions-0 }}$

Coral Triangle Initiative (CTI). 2019b. About CTI-CFF. Coral Triangle Initiative on Coral Reefs, Fisheries and Food Security. [online] URL: http://www.coraltriangleinitiative.org/about

Corson, C., K. I. MacDonald, and B. Neimark. 2013. Grabbing "green": markets, environmental governance and the materialization of natural capital. Human Geography 6(1):1-15.

Croes, R. 2012. Assessing tourism development from Sen's capability approach. Journal of Travel Research 51(5):542-554. https://doi.org/10.1177/0047287511431323

Dahuri, R. 2006. Pre-and post-tsunami coastal planning and land-use policies and issues in Indonesia. Pages 111-129 in J. S. Broadhead and R. N. Leslie, editors. Proceedings of the workshop on coastal area planning andmanagement in Asian tsunami-affected countries, 27-29 September 2006, Bangkok, Thailand. Food and Agriculture Organization of the United Nations, Regional Office for Asia and the Pacific, Bangkok, Thailand.

de Nooy, W. 2013. Communication in natural resource management: agreement between and disagreement within stakeholder groups. Ecology and Society 18(2):44. https://doi. org/10.5751/ES-05648-180244

Djohani, R. H. 1996. The Bajau: future marine park managers in Indonesia? Pages 260-268 in M. Parnwell and R. Bryant, editors. Environmental change in Southeast Asia: people, politics and sustainable change in South-East Asia. Routledge, London, UK.

Feltham-King, T., and C. Macleod. 2016. How content analysis may complement and extend the insights of discourse analysis: an example of research on constructions of abortion in South African newspapers 1978-2005. International Journal of Qualitative Methods 15(1). https://doi.org/10.1177/1609406915624575

Forsyth, T. 2003. Critical political ecology: the politics of environmental science. Routledge, London, UK. https://doi. org/10.4324/9780203017562

Gewin, V. 2015. Speak up for science. Nature 517(January 8):231-232.

Golden, J. S., J. Virdin, D. Nowacek, P. Halpin, L. Bennear, and P. G. Patil. 2017. Making sure the blue economy is green. Nature Ecology \& Evolution 1(2):0017. https://doi.org/10.1038/ s41559-016-0017

Green, L. 2015. Fisheries science, parliament and fishers' knowledge in South Africa: an attempt at scholarly diplomacy. Marine Policy 60:345-352. https://doi.org/10.1016/j.marpol.2014.08.002
Hall, C. M. 2007. Pro-poor tourism: Do tourism exchanges benefit primarily the countries of the South? Current Issues in Tourism 10(2):111-118. https://doi.org/10.1080/13683500708668426

Halpern, B. S., C. J. Klein, C. J. Brown, M. Beger, H. S. Grantham, S. Mangubhai, M. Ruckelshaus, V. J. Tulloch, M. Watts, C. White, and H. P. Possingham. 2013. Achieving the triple bottom line in the face of inherent trade-offs among social equity, economic return, and conservation. Proceedings of the National Academy of Sciences 110(15):6229-6234. https://doi.org/10.1073/pnas.1217689110

Hinch, T., and R. Butler. 2005. Indigenous tourism. Tourism Analysis 14(1):15-27. https://doi.org/10.3727/108354209788970117

Hornborg, A. 2009. Zero-sum world: challenges in conceptualizing environmental load displacement and ecologically unequal exchange in the world-system. International Journal of Comparative Sociology 50(3-4):237-262. https://doi. org/10.1177/0020715209105141

Hutchins, K., and N. Stormer. 2013. Articulating identity in and through Maine's north woods. Environmental Communication 7 (1):24-41. https://doi.org/10.1080/17524032.2012.749412

International Union for Conservation of Nature (IUCN). 2017. Protected areas: about. IUCN, Gland, Switzerland. [online] URL: https://www.iucn.org/theme/protected-areas/about

Jamal, T., and M. Eyre. 2003. Legitimation struggles in national park spaces: the Banff Bow Valley round table. Journal of Environmental Planning and Management 46(3):417-441. https:// doi.org/10.1080/0964056032000096866

King, T. J. 2005. Crisis of meanings: divergent experiences and perceptions of the marine environment in Victoria, Australia. Australian Journal of Anthropology 16(3):350-365. https://doi. org/10.1111/j.1835-9310.2005.tb00316.x

Konefal, J. 2013. Environmental movements, market-based approaches, and neoliberalization: a case study of the sustainable seafood movement. Organization \& Environment 26(3):336-352. https://doi.org/10.1177/1086026612467982

Likens, G. E. 2010. The role of science in decision making: Does evidence-based science drive environmental policy? Frontiers in Ecology and the Environment 8(6):e1-e9. https://doi.org/10.1890/090132

Longstaff, P. H., and S. U. Yang. 2008. Communication management and trust: their role in building resilience to "surprises" such as natural disasters, pandemic flu, and terrorism. Ecology and Society 13(1):3. https://doi.org/10.5751/ES-02232-130103

Loring, P. A. 2013. Alternative perspectives on the sustainability of Alaska's commercial fisheries. Conservation Biology 27 (1):55-63. https://doi.org/10.1111/j.1523-1739.2012.01938.x

McGaurr, L., B. Tranter, and L. Lester. 2015. Wilderness and the media politics of place branding. Environmental Communication 9(3):269-287. https://doi.org/10.1080/17524032.2014.919947

McGreavy, B., L. Lindenfeld, K. Hutchins, L. Silka, J. Leahy, and B. Zoellick. 2015. Communication and sustainability science teams as complex systems. Ecology and Society 20(1):2. https:// doi.org/10.5751/ES-06644-200102

Mous, P. J., J. S. Pet, Z. Arifin, R. Djohani, M. V. Erdmann, A. Halim, M. Knight, L. Pet-Soede, and G. Wiadnya. 2005. Policy needs to improve marine capture fisheries management and to 
define a role for marine protected areas in Indonesia. Fisheries Management and Ecology 12(4):259-268. https://doi.org/10.1111/ j.1365-2400.2005.00448.x

Musa, G. 2002. Sipadan: a SCUBA-diving paradise: an analysis of tourism impact, diver satisfaction and tourism management. Tourism Geographies 4(2):195-209. https://doi.org/10.1080/1461$\underline{6680210124927}$

Olson, J. 2010. Seeding nature, ceding culture: redefining the boundaries of the marine commons through spatial management and GIS. Geoforum 41(2):293-303. https://doi.org/10.1016/j. geoforum.2009.10.008

Pigg, S. L. 1992. Investing social categories through place: social representations and development in Nepal. Comparative Studies in Society and History 34(03):491-513. https://doi.org/10.1017/ $\underline{\mathrm{s} 0010417500017928}$

Rogers, P. P., K. F. Jalal, and J. A. Boyd. 2008. Chapter 1: From Malthus to sustainable development. Pages 19-39 in $A n$ Introduction to Sustainable Development. Earthscan, London, UK.

Saarman, E., M. Gleason, J. Ugoretz, S. Airamé, M. Carr, E. Fox, A. Frimodig, T. Mason, and J. Vasques. 2013. The role of science in supporting marine protected area network planning and design in California. Ocean \& Coastal Management 74:45-56. https://doi. org/10.1016/j.ocecoaman.2012.08.021

Scholl, S., M. Lahr-Kurten, and M. Redepenning. 2014. Considering the role of presence and absence in space constructions. Ethnography as methodology in human geography. Historical Social Research 39(2):51-67.

Silver, J. J., N. J. Gray, L. M. Campbell, L. W. Fairbanks, and R. L. Gruby. 2015. Blue economy and competing discourses in international oceans governance. Journal of Environment \& Development 24(2):135-160. https://doi.org/10.1177/1070496515580797

Speed Rossiter, J., G. H. Curti, C. M. Moreno, and D. LopézCarr. 2015. Marine-space assemblages: towards a different praxis of fisheries policy and management. Applied Geography 59:142-149. https://doi.org/10.1016/j.apgeog.2014.12.015

Steffek, J. 2009. Discursive legitimation in environmental governance. Forest Policy and Economics 11(5-6):313-318. https:// doi.org/10.1016/j.forpol.2009.04.003

Suarez, D., and C. Corson. 2013. Seizing center stage: ecosystem services, live, at the convention on biological diversity! Human Geography 6(1):64-79.

Tam, C.-L. 2015. Timing exclusion and communicating time: a spatial analysis of participation failure in an Indonesian MPA. Marine Policy 54:122-129. https://doi.org/10.1016/j.marpol.2015.01.001

Townsend, R. M. 2013. Engaging "others" in civic engagement through ethnography of communication. Journal of Applied Communication Research 41(2):202-208. https://doi. org/10.1080/00909882.2013.782420

UN Environment World Conservation Monitoring Centre and International Union for Conservation of Nature (UNEP-WCMC and IUCN). 2016. Protected planet report 2016. Cambridge, UK and Gland, Switzerland. von Heland, F., and J. Clifton. 2015. Whose threat counts? Conservation narratives in the Wakatobi National Park, Indonesia. Conservation and Society 13(2):154-165. https://doi. org/10.4103/0972-4923.164194

Williams, D. R. 2002. Leisure identities, globalization, and the politics of place. Journal of Leisure Research 34(4):351-367. https://doi.org/10.1080/00222216.2002.11949976

World Bank and United Nations Department of Economic and Social Affairs. 2017. The potential of the blue economy: increasing long-term benefits of the sustainable use of marine resources for small island developing states and coastal least developed countries. World Bank and United Nations Department of Economic and Social Affairs, Washington, D.C., USA. https://doi.org/10.1596/26843

World Wildlife Fund (WWF). 2018. Wakatobi. WWF, Washington, D.C., USA. [online] URL: http://www.wwf.or.id/en/ about wwf/wherewework/wakatobi/

Zheng, H., and G. Wang. 2014. Achieving ecological restoration by working with local people: a Chinese scholar seeks win-win paths. Ecology and Society 19(3):35. https://doi.org/10.5751/ ES-06995-190335 